\title{
Informatics System Design for the Management of Nutritional Supplementation in Body Modelling Sports
}

\author{
Dan MĂNESCU, Mihai DOINEA \\ Bucharest University of Economic Studies, Romania \\ dani_reisen2008@yahoo.com,mihai.doinea@ie.ase.ro
}

Issues regarding body modeling are debated. Facts regarding the nutrional oriented processes for body modeling are identified. The nutriments classes are presented and how the administration process is conducted based on several characteristics and which are the stages of succeeding these processes. An informatics system is designed for the management of nutritional supplementation in order to control the calories intake based on the intentisty of physical effort. The stages of development are presented, identifying optimization criteria for the security of the systems and its users.

Keywords: Informatics Systems, Supplementation, Nutrition, Body Modeling

$1^{1}$ Body Modeling

Sports activities are, by the day, an increasingly important component of our life. In the context of the automatic and cybernetic society today the sport is no longer practiced exclusively for performance and competition, but is rather a leisure activity, practiced for pleasure and for physical needs.

Body shaping sports (bodybuilding and fitness) do not make any other exception, gaining a more and more important role through what is offering to practitioners: strengthening of muscle, physical relaxation, health status, the formation of a positive attitude, awarding body aesthetics sense of self-confidence, dignity or personal gain respect from other people.

Anthropology tends more and more to explain the historical evolution of man through movement and though the human body is studied for thousands of years it continues to have many mysteries. Over time they have appeared on a number of questions that still await the answer: is it existing upper performance we can get? what sizes can exercise to develop the bodies? or which is the superior limit of the effort?

The impact it has in recent times the physical upkeep of the human life cycle with the weights as a cornerstone of the harmonization of bio somatic, but at the same time as a strong weapon against disease and aging. The results and benefits of this type of training have done that now, in the $21 \mathrm{st}$ century, in Western Europe, one in six people have subscribed to a physical maintenance, and in the US there are over 30 million practitioners.

The advancement of technology in a world increasingly concerned with science makes man to be based primarily on the grey matter, unadapting the body as quickly as, so coming against the lack of physical activity required by modern society. In the era of speed and information man becomes a kind of prisoner, basically "linked" to the working office, so appearance of back pain, shoulders rounded, obesity, impaired blood circulation or lack of energy and mobility are becoming such a natural consequences. At the same time, however, there are very strong arguments that we have refocused the priorities, heading towards the US steps by practicing systematic exercise.

Development and diversification of the disease have forced the world to recognize the importance of physical activity, and the amazing results of the workout with weights have convinced that fitness and bodybuilding is a very effective form of preventive medicine and the remedy of a long series of illnesses. Why? Because a body trained means mobility, a high rate of metabolism and greater resistance against the accumulation of fat. Muscles provide solid protection and a full program of weight training strengthens the whole body, 
regardless of age or level of athletic training. In this regard it is recognized that women lose approximately $25 \%$ of bone mass for up to 75 years, thereby exposing themselves to the risk of fractures. This can be prevented with the help of the training. Studies of the origins Tufts (Nedford, Massachusetts) performed on postmenopausal women show that strength training strengthens the bones of the spine and the hips exposed to fractures. Also the training for bodybuilding and strength is significantly reducing the chances of falls that would have disastrous effects.

Regarding to other health issues, clinical reports show that training with weights reduce levels of LDL cholesterol, and "negative" studies at John Hopkins University in Baltimore, Maryland, show that the same type of workout significantly speeds up transit time of food in the large intestine, reducing the possibility that debris may cause blockages or even colon cancer.

The very concern of medical prevention, relief and healing of diseases took a decisive turn in recent years. A recent report indicates that mortality, cardiovascular disease, some cancers, osteoporosis, diabetes and mental health are greatly influenced by exercise. Simply, exercise is the ideal form of preventive medicine, and a healthy body becomes a barrier to disease which ultimately survival.

Further research has shown that developing and maintaining muscle mass is the solution to avoid the loss of immunity and atrophy of diseases often associated with the aging process. As hormone levels and their activity decreases with age is installing the senile atrophy. After the age of 30 years the musculature begins to decrease, after 50 even climbing stairs becomes a problem and as aging lost part of the ramifications that go to different nerve tissues, so at 70 years of age $40 \%$ of the muscle mass is lost, fortunately not forever. While studies have shown that drug therapy based on the introduction of additional hormone helps to maintain bone mass and increases the feeling of good physical condition, experience gained over the decades in bodybuilding shows that regular exercise and proper nutritional supplementation can produce exactly the same results [1].

If the theory is complete, training is probably at its peak by the innovations of the last decade and discoveries made in the field of nutrition and nutritional supplements. According to estimates from the specialists in the development of nutrition and muscle supplementation affects final results in a proportion of $70-75 \%$. Therefore, and from including the idea that the human body is a sophisticated piece of work that needs a fuel complex to function properly, quality of this fuel directly affects the results.

As a result of extensive research carried out by the specialized centers of nutrition, over a number of years but which continues today, it failed to get some dishes called nutritional supplements, which focused in a small volume of a large amount of valuable substances. This release of an exaggerated athlete of foods, ensuring a proper feeding much easier. In the category of nutritional supplements are amino acids, protein concentrates, vitamins and minerals. They were discovered and a host of other supplements of vegetable or animal origin, which are to stimulate the growth of the body.

It is very important to make the distinction between a drug and a dietary supplement, often producing confusion in this regard. A drug is a substance that is prescribed in order to create a certain effect in an organ, in a cell or organism, and it manages to a particular disease or condition, as a nutritional supplement is a product obtained from natural foods, from which the main nutrients were removed, designed to supply energy or replace molecular elements. It's actually a concentrated form of food of the highest quality. At the present not only athletes consume such products but also sedentary individuals, desiring to provide a quick, convenient food and containing energy requirements and the quality of a meal.

\section{Active Principles of Nutritional Supplementation}


Nutritional supplements can be found in various presentation forms or combinations, depending on the intended use of the product in question and the company producing. In the category of really valuable add-ons for shaping the body enters: aminocids, protein, vitamins and minerals.

Proteins-originally were released on Western market concentrated protein extracted from the milk, egg white, soy and whey. The form in which they most often can be found is a fine powder (like milk powder) with different flavors - vanilla, chocolate, cocoa, etc., and concentrations can go up to $99 \%$ of the mass of the protein product. Advantages of using these protein concentrates in the food are: the possibility of introducing into the body of high-quality protein without the unwanted fat, usually associated with the proteins in foods - such as milk, meat, egg, etc.; the opportunity to give your body the protein no longer requires a long mechanical processing at the level of the oral cavity and stomach being only necessary proteins, i.e. disposal of hydration in amino acids followed by absorption; last but not least, the possibility of having a source of carry it easy due to the concentration and easy to use; just protein powder mixed with water or another liquid and consumed as such.

Quite often, the desire to ensure a perfect food, some companies add vitamins, protein content of mineral salts, sugars (carbohydrates) with slow absorption. Sometimes even natural stimulants such as ginseng, pollen etc.

The main source of protein for nutritional supplements is milk.

Milk protein derives almost always from cow's milk and is available as whole milk protein, whey protein and casein. It is time for nature to support the childhood a period of life in which are the highest requirements for growth-is an ideal place for supplements. Whey protein has been reported as the supreme form of protein thanks to its composition in essential amino acids, branched-chain amino acids (BCAA), sulphur amino acids, as well as taste, mix and stability in liquids. The fact that it's rapidly absorbed, especially in comparison with casein, was considered a plus.

Essentially, whey is the liquid that remain after casein and fat have been removed from the milk. Casein separates from whey manufacturers using acids or specialized filtration methods. The first method acids can damage valuable whey protein fractions. Lower prices on these products may indicate that the process has been used with acid and protein in question is not of the highest quality.

Casein - the best of two types of casein are in the form of an aggregate of small spheres of protein molecules, and the type that is found in breast milk protein (which is approximately $80 \%$ casein, and $20 \%$ whey). These two types are completely denatured and contain minerals (calcium, magnesium, phosphorus, potassium) that are found inside the cluster of protein molecules.

Soy protein - downplayed some time ago, soy protein was reconsidered due to the new processing have made it more palatable and digestible. Soy protein has some unique features that separates proteins of animal origin. Soy is the only dietary source of two particles many isoflavones: genisteina and diadzeina. Research shows that they are in part responsible for the actions of the antioxidant properties of soybean, stimulating the thyroid metabolism, cancer prevention, reduction of risk factors of cardiovascular disease, and maintaining bone mass. As the milk protein, soy protein is dependent on the method of processing. Some use mixtures of ethanol/water walks away isoflavones. Ethanol (alcohol) is at fault in these ways-it distorts the soy protein. The protein in the egg, the white part of egg, was used as an example of protein; This has led to the perception that the protein in the egg dustable powders are the best supplement. However, there are fewer protein of egg products on the market because they are more expensive than any other pure proteins, in particular the emergence of dustable powders following pure whey protein. Egg proteins are normally added protein, dustable powders following in 
small quantities (less than $5 \%$ of the total proteins), to win the trust of the buyer. Protein blends are becoming increasingly more sophisticated by the day. Manufacturing techniques, including a mixture of proteins, predigested and strengthen with amino acids, are used to produce or improve various proteins.

Time release proteins, providing a continuous stream of extended and the blood protein and muscle is the primary goal of suplimentatiei in bodybuilding. A common trend in this industry is to claim a high content of protein per serving (sometimes up to 60 g.). In liquid form they could pass through the intestines very quickly perhaps too fast to be effective even if they consume 40 grams or less per serving. These products are great for anytime, day, night meal or between meals.

Predigested proteins - who thinks seriously to increase the muscular mass, and in addition they eat 150-200 grams of protein and other solids daily 100 grams of protein in the form of liquid, must know that the intestines are working just as hard as the muscles. Thus the enzyme that digested proteins may decrease. Intense exercise can cause some problems of the intestines through various forms of physiological fatigue. Let's say you need a diet that includes more proteins to exceed the current level, but the athlete does not wish to stress the intestines. Need something more easy to digest. The next break is supposed to have a high content of di-and tripeptides (two or three amino acids connected with each other), approximately 30-40\%. Recent studies show that these peptides are important because when taken in significant quantities increase nitrogen retention (so have anabolic effect). High levels of di and the tripeptide in a protein (as opposed to minuscule levels of $5-10 \%$ of the total protein, for example) issued a more favorable and more constant of amino acids in the blood system. They do it faster and with lower quantities used for energy compared with equal quantities of protein or amino acids. In addition, they may increase the serum albumin, which acts as a repository for amino acids, and is of very high importance in maintaining water content in the blood. Any time is good to take those protein predigested, especially if already picking up large quantities of protein every day. It would be beneficial in particular after training.

Peptides and amino acids - two things led to the development of a hydrolysed proteins rich in glutamine: first, the increase in popularity of glutamin as ergogenic aid for recovery and growth and, secondly, recognition of the fact that the hydrolysed proteins may increase the absorption of amino acids better than taxes levied equivalent amount of whole protein or amino acids in free form. Peptide glutamine is stable-the acid in your stomach for example - and absorbed and easy mid-cycle. In order to obtain enough glutamine, supplements are fortified with glutamine. You searched for peptide glutamine or L-glutamine in the list of ingredients, not glutamic acid or "glutamine precursors", because the latter are not the same thing with glutamine. Lglutamine is over $95 \%$ glutamine peptide, while glutamine contains only $30 \%$ glutamine. Furthermore, if a label of a product of tissue-specific peptide of glutamine, this product does not contain 3 grams of usable glutamine. Glutamine has not only anabolic and anticatabolic actions in the body, but also increases the value of the other proteins in the process of building muscles. When the glutamine is reduced, developing muscle becomes almost impossible.

Other amino acids used frequently in strengthening protein supplements are amino acids with branched-chain (BCAA), which can be used as an energy source when blood sugar and glycogen in the muscle diminishes. When there is a deficiency of BCAA's body begins to destroy their own structures, starting with the fillet. It should be noted that whey protein contains around 20\% BCAA, so consumption of 3-4 portions of concentrated whey protein cancels the need to take the BCAA separately. 
Amino acids-protein concentrates, after the next step was the emergence of amino acid in the form of capsules or less powder. The major advantage in relation to protein is that the concentrates are ready for absorption. This is particularly important after workout, when needs in amino acids of the body is acute. Being very quickly assimilated into the body ensure the construction and repair of tissues very quickly. In this category the most valued are those extracted from milk and eggs.

Of those 22 amino acids the most valued are Leucine, Isoleucine and Moses, also known under the name of BCAA (branched chain amino acids). They are absorbed directly into the bloodstream without being processed in the liver. Their value is given by the fact that the composition of the muscle tissue at the rate of 30 to $35 \%$. Shall be taken before and immediately after training within an hour.

Amino acids are important as independent elements, thanks to stimulate anabolic processes. Thus - arginine stimulates the secretion of growth hormone (IGH) who is deeply involved in building muscles and burning fat; and has the same influence as the ornithine and arginine but is much stronger.

Through the use of amino acid shortens the time between the end of your workout and the time of their absorption if coming from protein concentrates, and the difference is even more dramatic, even if compared with the use of a common foodstuff such as for example the meat to be processed mechanically in the mouth at first and then in the stomach, then place hidrolisation proteins. Noting that immediately after workout foods placed in the stomach are not digested, so functions are not normal for a while (up to 1 hour) because blood is in the muscles used during training for the different processes are absolutely indispensable.

There are 17 amino acids, which are divided into essential and unessential. 8 essential ones are as follows: isoleucine, leucine, lysine, methionine, phenylalanine, tryptophan, tiozina, EfE. Theoretically, a diet rich in these eight amino acids, the human body may be able to produce all the other amino acids needed for muscle growth, hormones, enzymes, etc. However, the theaters are considered to be essential for the other 4 amino acids. They are: glutamine, taurine, arginine, alanin.

Considered complete proteins by nutritionists and dietologists are in fact incomplete for athletes, who need those quantities of essential amino acids required by the body during exercise. A diet rich in protein as those contained in the chicken and milk is not always the best way for a fair and balanced administration of amino acids. Just by filling in with proteins containing and sprayed the amino acids glutamine and taurine that can ensure the success of your muscle growth. In a more colloquial language, we can distinguish the noble from the proteins that are not noble. In the first case it is the proteins that contain all the essential amino acids derived from milk, meat, eggs, fish. There is poor food in tryptophan, lysine and methionine, such as wheat and vegetables, for example.

But what happens with amino acids and proteins in our body? As soon as it is consumed, proteins in the stomach activates an enzyme called pepsin. Long chains of amino acids are disposed in short chains, and partially protein digestion continues in the intestine where pancreatic enzymes will unfurl once the chains of amino acids in the polypeptides. In the end they will be disposed of proteins one at a time by another group of enzymes in dipeptides tripeptides, or chains of two or three amino acids. They will be absorbed into the circulation of the blood and transported to the liver, where one in four will be transformed in a different amino acid, used for the formation of specific proteins. Not all amino acids will be retained in the body. It depends on the needs of the moment: for a bodybuilder's primary objective is to procure the necessary reconstruction of muscle protein body after an intense workout. The required amount of a sporty intermediate level is approximately 200-300 g of protein per day, split into five or six small portions. All excess protein is partially converted to nitrate and eliminated 
through the urine, while the carbon is stored in the form of fats (contrary to what some believe, and excess protein fattens). In the end, all amino acids are disrupted in what is called recycling protein, which consists of anabolic shape (construction of muscle tissue) and catabolic (destruction of muscle tissue). The most commonly used amino acids are those with branched-chain, but is not always giving the best results. In certain circumstances, for example, tryptophan and tyrosine has a direct effect on neurotransmitters. While using the amino acids glutamine and arginine that is likely to inhibit growth hormone secretion. Science has not yet pronounced on all you need to know about this type of integration, and even less about her role in muscle growth.

Vitamins - belonging to the category of substances with enzymes (starter), which make various chemical reactions, particularly those of catalyst. These reactions occur continually in his lifetime, in order to ensure the growth and reproduction of the organism, and the restoration of wear suffered. Vitamins, along with the hormones and enzymes form the group biocatalysts which governs all the reactions of the human body. A fall of vitamins can cause a deterioration of health, and in severe cases may cause even death. Although they are required in very small quantities (milligrams), vitamins can't miss in human nutrition. Decrease the amount of vitamins in circulation for a period of time, called hypovitaminosis, produces disorder in the conduct of normal processes of the body. The lack of vitamins in food causes a range of diseases, called avitaminosis (e.g., xeroftalmy, lack of vitamin A, beriberi in the absence of vitamin c. scurvy in the absence of vitamin $\mathrm{C}$, rickets in the absence of vitamin D). No excessive consumption of vitamins is not shown, because it produces hypervitaminosis, accompanied by disorder. So for example, hypervitaminosis A and D is accompanied by a number of disorders like kidney failure, phenomena: digestive (nausea, vomiting, constipation), nervous disorders and cardiovascular disease, due to the disturbance of the metabolism of phosphorus molybdatesunny; excess vitamin $\mathrm{C}$ and those in Group $\mathrm{B}$, after a married to their removal, followed by digestive disorders and a paradoxical hypovitaminosis. There are currently 13 vitamins, denoted by letters of the alphabet. In addition to vitamins $\mathrm{A}, \mathrm{C}, \mathrm{D}, \mathrm{E}, \mathrm{K}$, there are 8 in Group B vitamins: thiamine (B1), riboflavin (B2), Pyridoxine (B6), cyanocobalamin (B12), biotin (H, B7), folic acid (B4), niacin (PP, B3), Pantothenic acid (B5). They were categorized into two groups: water soluble-those that dissolve in water (B complex, and vitamin C) and fat-solublethose that dissolve in fats (e.g., vitamins A, D, E, K).

Water soluble vitamins: are very common in nature, and very sensitive to the action of the external environment (oxygen, temperature, humidity, light, radiation, etc.); pass easily in culinary processing water and boiling; requires a normal gastric acidity, in order to be released from food ingested and to not be destroyed; Therefore, their management before the meal, when the secretion of acid is reduced (gastric juice slightly), making them unusable by the body; after absorption would ease in the blood, tissue and humors (welders, urine, placenta, mammary glands); It is stored in the body and therefore lacking in signs appear; participate in liberating energy processes and are therefore also called enzyme-vitamins.

Fat-soluble vitamins: are less spreaded in nature, are less sensitive to the action of external factors, with the exception of vitamin A, which is sensitive to the action of oxygen; fall harder during the processing of food; for their absorption is a normal secretion of bile and pancreatic juices, necessary digestion of fats; bowel sped reduce their use; go harder in tissues and humours; do not remove the urine; their lead to overload the storage in the liver, in which case the signs are lacking; attending predominantly at morphogenetic processes with similar hormone action, and that's why they are called the hormonic vitamins.

The human body is able to get the vitamins from the external environment (through food) 
and the internal, by forming inside the body of vitamins. For example, vitamin A from carotene ingested by vegetables (carrots, tomatoes); Vitamin D through exposure to ultraviolet rays; Vitamin $\mathrm{K}$ and vitamins of the $\mathrm{B}$ group by the action of microbial flora in the large intestine. The necessity of vitamins is determined by age, gender, and even by the weather conditions in which they operate. Except for the determination of blood concentration of vitamins, there is a strictly objective criterion that specifies the appropriate intake of vitamins. The athletes need vitamins is much higher about achieving sports results, reducing fatigue and shortening recovery time after exertion when receiving increased amounts of vitamin $C$, B1, B6, etc. Ingesting quantities of vitamins lead normal, besides the increase in capacity of the organism, and the resistance of the disease. It is advisable to consume vitamins in the form of natural foods containing them, because their effect is much better than when they are ingested in the form. Preserving vitamins in their natural state is of great importance. Fat-soluble vitamins are destroyed by oxidation where are kept in direct contact with the air, sunlight and high temperature. Water soluble vitamins, particularly vitamin $\mathrm{C}$ is destroyed by cooking. Vitamins of the B group enters the constitution as fermentes enzymes. For example, vitamin $\mathrm{B} 1$, together with proteins, is in the structure of more than 20 enzymes.

Minerals - belong to the category of trofins with the plastic part (the salts calcium, phosphorus, magnesium, sodium, potassium) and catalytic converter (copper salts, iodine, cobalt, iron). Minerals are essential substances for the musculoskeletal system and multiple biological actions.

The muscular effort is influenced by the environment in which the mineral stock company carries out. At the same time the muscular effort causes changes in the balance of mineral elements (remove them once with perspiration). Through food, some mineral elements are made in large quantities (chlorine, sodium, calcium, potassium, sulfur), and some in small quantities (copper, zinc, manganese, iodine, fluoride). Remove them from the body through urine and sweat, the latter gaining particular importance in efforts to sweat much.

Minerals are involved in transmitting nerve in muscular contraction process and enzyme activity. The absence or decrease of the quantity of minerals causes conditions like anemia (lack of iron) or hypothyroidism (lack of iodine). It has been suggested that a deficiency of zinc would be responsible for a decrease in immune system response and thus a greater receptivity to the pharyngeal infections, rhinitis, or lung disease. Increase the efforts of minerals involved in tissue regeneration processes, therefore athletes need a further multiminerals.

A mineral deficiency, or a single vitamins, can disrupt over a thousand chemical and enzymatic processes of the body. Each of these minerals are responsible for decades of biochemical reactions, including the formation of hormones. A daily intake of multivitamins have not only the advantage that provides the body with all the substances it needs, but they have the benefit of working together, to act together, and the mutual effect of potency may last.

Supplementation should compensate for the losses through urine and sweat and improve the body's mineral status. Can be done either by product type multiminerals or rehydration solutions. Mineral elements whose status is more often disturbed in the human body are iron, zinc, and magnesium. To improve performance are also added to this list and baking soda, phosphates and trace elements supplementation with these items is recommended during periods of intense workout or in any situation where it is necessary to limit food intake (period of defining, or competitions where you have made the weight class). It is recommended also for the cardio workouts. List of minerals includes the following elements: sodium, potassium, magnesium, calcium, phosphorus, iron, zinc, sulfur, iodine, copper, chromium and selenium.

\section{Informatics System Structure}


The necessity has emerged from the need of having a complex system in order to implement security aspects, measuring effects and testing security optimization models. The primary objective is to help bodybuilders to adjust and measure their body building indicators such as body mass index, basal metabolic rate, lean body mass, daily calorie intake influenced by the effort intensity and a healthy and balanced menu split into breakfast, lunch and dinner.

For helping individuals on evaluating their workout programs a web based distributed application was developed offering online support for the ones who are willing to have an efficient management on their exercise calendar.

The bodybuilding indexes calculated by the application could be used by users to measure the effects of their own workout program in terms of weight, daily calorie need and improvement. In this way users adjust the exercises in order to obtain a desired effect upon their muscular system, growing rate or upon their general health.

In this new approach of knowledge based society where technology is at the top of all human processes and physical activities are part of the past, the adjustments in our daily food table must counterweight the lack of physical effort. Inactivity given by our new way of life, sitting in an office, in front of a computer and doing things that only stimulate our intelligence, is compensated with a strictly diet or with a regular physical training program. The effort correlation with the daily calorie consumption is a complex bound in which many types of effort should be evaluated like:

- physical effort is one of the most researched areas; scientist, physicians, sportsmen and other interested parties had developed a whole system of indicators; trying to get the best out of the human body, they measured calories consumption in human regular activities and training exercises and classified them by effort intensity;

- neurological effort is a part of cognitive intensive effort has its word in the process of daily calorie consumption; one of the best practice examples is the student session period when majority students change their way of life for a couple of weeks; in this time, intensive cognitive effort is made which will request a high amount of proteins, which are the main resource for the brain to function at full capacity; doing so, using more proteins as fuel for the thinking machine, will alter the established equilibrium, resulting in less food per capita per day; at the end of the students session period they will fill a change in their weight status in plus or in minus;

- emotional effort is also a direct factor which affects the daily calorie consumption and one of great importance; emotional effort lead people in or out of medical problems by influencing their meals.

It is well known that are persons, emotional eaters, in which the desire to eat is almost totally dependent on their daily activities, their hunger is purely emotional based. This kind of disorder appear suddenly as react to a stressful event and produces appetite for a particularly type of food.

Stress is one of the most important reasons due to which people get hungry. It is known that when we are stressed a whole chain of reaction starts in our body. First of all the stress increases the level of cortisol in our body, a hormone that is triggered by stress and which is telling to our cells to release rapidly an important amount of carbohydrates and fats. That's why that energy released must be compensated with another one which must enter, to preserve the balance. As a response of that chain of reactions, our body screams for food, especially sweets and salty foods from which it absorbs rapidly the amount of energy spent as a reaction to stress. The calorie consumption has shifted the balance in favour of the calorie input process rather than the calorie output. This means that more are the calories that are entering inside our metabolism than the ones that are leaving by means of natural processing like physical 
exercises. This anomaly is the cause of all our metabolism dysfunctions, ultimately leading to different types of illnesses. The total intake on daily basis is dependent upon the following factors for each individual: age, sex, weight and height, values that serve afterwards as input data for the process of calculating the daily calorie consumption and the menu configurations for the desired level of effort. The application for daily calorie consumption is meant to give help to individuals who want regularly check their calorie schedule, building them menus based on the intensity effort, daily set it.

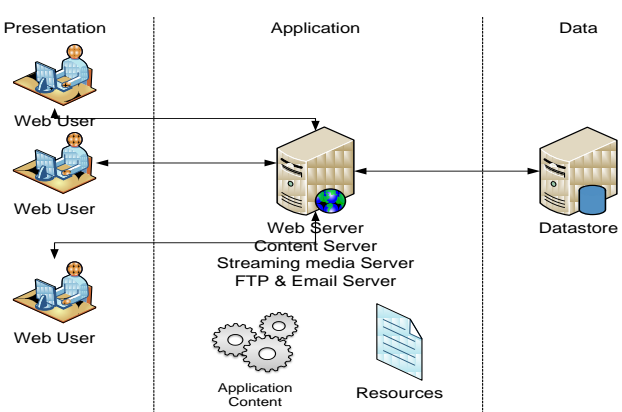

Fig. 1. The Three-Tier Web Based Distributed Application [2]
The framework is built on several layers having a three-tier distributed architecture [BODO10], Figure 1. The three layers are represented by:

- presentation layer- is given by the interface of the application designed to help users resolve their needs;

- database layer - is represented by a Oracle Database Scheme which stores all the application data;

- application layer - contains all the distributed application main code composed of C\# classes.

Users have access to the following functions in a one way informational flow with the possibility to come back in different region of the process as presented in the Figure 2:

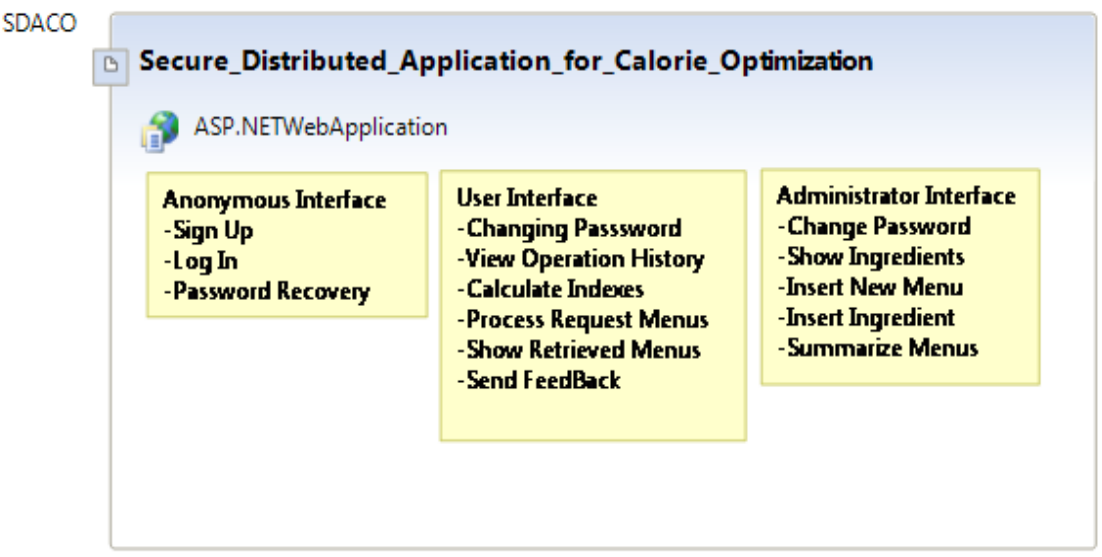

Fig. 2. Presentation Layer for SDACO

The presentation layer is described by the user's interface in which input data is entered like:

- height and weight, expressed either in imperial or metric units;

- age in years;

- sex which will make the difference between several bodybuilders metrics;
- activity effort type expressed by a list of five different levels, each one giving examples of several activities for it;

- data interval for generating the combinations of menu.

The application layer is defined by the totality of the server-side and client-side source code which intermediates between user's actions and the database layer. The application layer is written using different 
programming and description languages which are cooperating in achieving the higher level of efficiency and performance, such as:

- C Sharp, C\# implemented in the .Net Framework as a managed code language running under a CLR, Common Language Runtime virtual machine;

- AJAX for efficiently achieve all the asynchronous procedures defined in the application; AJAX stands for Asynchronous JavaScript and XML;

- JavaScript for successfully implementing client-side functions;
- HTML, a mark-up language over which ASPX is implemented;

- CSS, Cascading Style Sheets for managing the application's layout.

The database layer contains two categories of information:

- user related information like accounts, roles and memberships along with a history table of each operation undertaken in application;

- menu related information like ingredients, menus, allergies, categories.

In the Figure 3, it is represented a partial internal structure of the database, in which stores this information being processed later by the application layer:

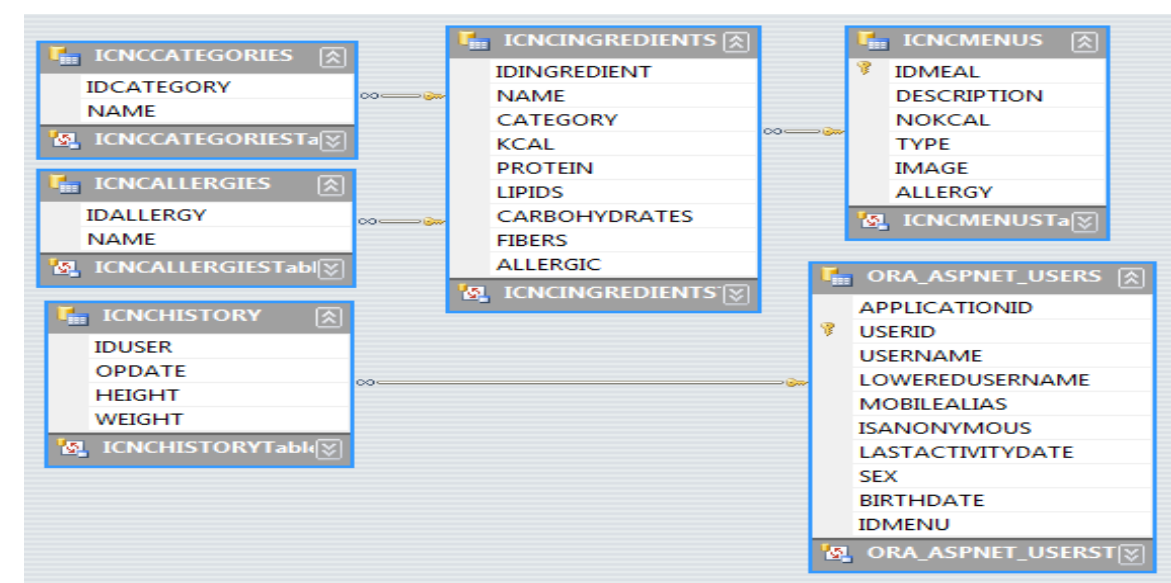

Fig. 3. Oracle Database Partial Structure

This approach shows how easily, with the help of technology, people store information about their calories consumption or about the number of calories found in a particular type of food rapidly, with no effort. There is lots of useful information which is stored in a database. A specific type of aliment contains information about food energy represented by the number of calories, fats specified in grams per unit, saturated fats per unit, carbohydrates in grams per unit, proteins in grams per unit, cholesterol in milligrams per unit, fibers and sodium.

The application is storing information about the main ingredients and their nutriments as they were classified and measured in [3]. The application is using ingredients classified and presented in categories like: vegetables, meat, fish, milk, cheese, nuts, drinks, beans, rice, fruits, cereals and others.

In [4] a food calorie list separated by the type of aliment, in which they are found, is presented, like: vegetables, meat, fish, milk, cheese, nuts, alcohol, beans, rice, fruits, cereals, pizza and more others.

In the following figure, detailed in [5], it is presented the number of calories that a person of various weights burn per minute during different regular activities. 


\begin{tabular}{|l|r|r|r|r|}
\hline \multicolumn{2}{|c|}{$120 \mathrm{lb}}$. & $140 \mathrm{lb}$. & \multicolumn{1}{c|}{$160 \mathrm{lb}}$. & $180 \mathrm{lb}$ \\
\hline Activity Calories/min. & 7.5 & 8.8 & 10.0 & 11.3 \\
\hline Bowketball & 1.2 & 1.4 & 1.6 & 1.9 \\
\hline Cycling (10 MPH) & 5.5 & 6.4 & 7.3 & 8.2 \\
\hline Dancing (aerobic) & 7.4 & 8.6 & 9.8 & 11.1 \\
\hline Dancing (social) & 2.9 & 3.3 & 3.7 & 4.2 \\
\hline Gardening & 5.0 & 5.9 & 6.7 & 7.5 \\
\hline Golf (pull/carry clubs) & 4.6 & 5.4 & 6.2 & 7.0 \\
\hline Golf (power cart) & 2.1 & 2.5 & 2.8 & 3.2 \\
\hline Hiking & 4.5 & 5.2 & 6.0 & 6.7 \\
\hline Jogging & 9.3 & 10.8 & 12.4 & 13.9 \\
\hline Running & 11.4 & 13.2 & 15.1 & 17.0 \\
\hline Sitting, quietly & 1.2 & 1.3 & 1.5 & 1.7 \\
\hline Skating (ice and roller) & 5.9 & 6.9 & 7.9 & 8.8 \\
\hline Skiing (cross country) & 7.5 & 8.8 & 10.0 & 11.3 \\
\hline Skiing (water and downhil) & 5.7 & 6.6 & 7.6 & 8.5 \\
\hline Swimming (crawl, moderate pace) & 7.8 & 9.0 & 10.3 & 11.6 \\
\hline Tennis & 6.0 & 6.9 & 7.9 & 8.9 \\
\hline Walking & 6.5 & 7.6 & 8.7 & 9.7 \\
\hline Weight Training & 6.6 & 7.6 & 8.7 & 9.8 \\
\hline
\end{tabular}

Fig. 4. Calorie burn per activity by weight [5]

Based on this kind of data, complex systems of measuring have been developed, indicators like BMI - Body Mass Index, FMI - Fat Mass Index, BMR - Basal Metabolic Rate have been used to measure all the aspects of physical effort to help people understand better the way how their bodies work.

\section{Development Stages and Optimization Considerations}

Optimization is a continuous process of getting significant better results from a previous state.

Trying to get the best out of the human body they measured calories consumption in human regular activities and training exercises and classified them by effort intensity.

Studies had showed that females need for calorie burning is much lower than male. This is due to the fact that female constitution is different from male and they tend to store fats in the hip section. This means that a woman will consume almost a number of calories equal to a man but from different sources like meals and fat deposits. The difference between the two sexes is that a man has a much higher metabolism rate and the daily calorie intake is processed much rapidly comparative to a woman.

For daily calorie consumption, a distributed application was build helping to determine the body calorie needs based on several input data like weight, height and age. Optimization regarding the daily calorie expenditure is related to the following concepts presented in [6], [7]:

- BMI - Body Mass Index, is a statistical index which compares a person's weight and height; this index is relevant in estimating a healthy weight;

- BMR - Basal Metabolic Rate is the amount of energy expended while at rest in a neutrally temperate environment; this release of energy in this state is sufficient only for the functioning of the vital organs;

- FMI - Fat Mass Index is the amount of fat reported to the muscular mass and the total weight of a person;

- LBM - Lean Body Mass represents mass of the body - the fat.

The BMI index can be calculated based on the following formula in International Systems of Units - SI:

$$
\mathrm{BMI}=\frac{\text { weight }(\mathrm{Kg})}{\text { height }^{2}\left(\mathrm{~cm}^{2}\right)}
$$

Body Mass Index values are age-independent and the same for male and female. However, BMI may not correspond to the same degree of fatness in different populations due to different body proportions. Various studies have been made, correlating BMI with the individual health status, based also on racial criteria. 
Based on the values that result from the following formula a person can be classified in one of the following categories presented in [8], Table 1:

Table 1. BMI ranges [8]

\begin{tabular}{|c|c|}
\hline \multicolumn{1}{|c|}{ Classification } & BMI \\
\hline Underweight & $<\mathbf{1 8 . 5 0}$ \\
\hline Severe thinness & $<16.00$ \\
\hline Moderate thinness & $16.00-16.99$ \\
\hline Mild thinness & $17.00-18.49$ \\
\hline Normal range & $\mathbf{1 8 . 5 0}-\mathbf{2 4 . 9 9}$ \\
\hline Overweight & $\geq \mathbf{2 5 . 0 0}$ \\
\hline Pre-obese & $25.00-29.99$ \\
\hline Obese & $\geq \mathbf{3 0 . 0 0}$ \\
\hline Obese class I & $30.00-34-99$ \\
\hline Obese class II & $35.00-39.99$ \\
\hline Obese class III & $>40.00$ \\
\hline
\end{tabular}

Basal Metabolic Rate is calculated different for man and woman. This is due to differences in metabolic activities and processes that appear on both genders.

Basal Metabolic Rate has the following formula:

- for man:

$$
\begin{aligned}
B M R=\left(\frac{13.7516 \times m}{1(\mathrm{~kg})}+\frac{5.0033 \times h}{1(\mathrm{~cm})}\right. \\
\left.\quad-\frac{6.7550 \times a}{1(\text { year })}+66.4730\right) \frac{\mathrm{kcal}}{\text { day }}
\end{aligned}
$$

- for woman:

$$
\begin{gathered}
B M R=\left(\frac{9.5634 \times m}{1(k g)}+\frac{1.8496 \times h}{1(\mathrm{~cm})}\right. \\
-\frac{4.6756 \times a}{1(\text { year })} \\
+655.0955) \frac{\mathrm{kcal}}{\text { day }}
\end{gathered}
$$

Calculating BMR, for people who suffer of metabolic diseases and are overweight or obese, with the formula presented above can be insignificant because of their excess fat deposits. As optimization the Basal Metabolic Rate is calculated based on the formula:

$$
B M R=370+(21.6 \times L B M)
$$

where LBM represents Lean Body Mass, differentiated by gender. The LBM is calculated as follows:

- for men:

$$
\begin{aligned}
\text { LBM }=(1.10 & \times \text { Weight }(\mathrm{kg}))-128 \\
& \times \frac{\text { Weight }^{2}\left(\mathrm{~kg}^{2}\right)}{\operatorname{Height}^{2}\left(\mathrm{~m}^{2}\right)}
\end{aligned}
$$

- for women:

$$
\begin{aligned}
\text { LBM }=(1.07 & \times \text { Weight }(\mathrm{kg}))-148 \\
& \times \frac{\text { Weight }^{2}\left(\mathrm{~kg}^{2}\right)}{\text { Height }^{2}\left(\mathrm{~m}^{2}\right)}
\end{aligned}
$$

\begin{tabular}{|c|c|c|c|c|c|}
\hline Gender/Indicators & $\begin{array}{c}\text { BMR } \\
1\end{array}$ & $\begin{array}{c}\text { LBM } \\
2\end{array}$ & $\begin{array}{c}\text { Weight } \\
\mathbf{3} \\
\end{array}$ & $\begin{array}{c}\text { Body Fat } \\
\text { (Weight - LBM) } \\
4=3-2\end{array}$ & $\begin{array}{c}\text { BFP -Body Fat } \\
\text { Percentage } \\
5=4 / 3\end{array}$ \\
\hline Men & 2088 & 57 & 69 & 12 & $17.39 \%$ \\
\hline Women & 1765 & 52 & 69 & 17 & $24.63 \%$ \\
\hline
\end{tabular}

Based on the a set of figures used in calculating this indicators, correlations can be made resulting that unlike female, male have a higher metabolic rate and a surplus of fats much lower than females. In the Table 2 results are presented in comparison:

Table 2. Correlation results

Based on this value of fat percentage we can tell the category in which an individual is, just like the BMI classification, as presented in Table 3:
Table 3. Fat percentage category

\begin{tabular}{|l|c|c|}
\hline \multicolumn{1}{|c|}{ Category } & Men & Women \\
\hline Essential fat & $2-4 \%$ & $10-12 \%$ \\
\hline Athletes & $6-13 \%$ & $14-20 \%$ \\
\hline Fitness & $14-17 \%$ & $21-24 \%$ \\
\hline Acceptable & $18-26 \%$ & $25-31 \%$ \\
\hline Overweight & $27-37 \%$ & $32-41 \%$ \\
\hline Obese & $38 \%+$ & $42 \%$ \\
\hline
\end{tabular}


From this we can tell that both man and woman are situated at the end of the Fitness category with a value of $17.39 \%$ for man, respective $24.63 \%$ for woman.

This approach is useful for determining our body's needs for calories and gives precise directions in lowering, maintaining or growing our body fat mass implicit our weight. There are different methods and techniques for optimizing the way we use our daily calorie intake to have a healthy and happy life.

One of the methods used for optimization is by introducing the concept of vectors found in literature. In these directions various numbers of vectors can be defined. The concept of vector optimization is given by the fact that different body building aspects could be joined to emphasis a path that could be followed for obtaining specific results such as:

- slowing the aging process;

- achieving performance in specific workout programs;

- a good and healthy physic influence mental efficiency;

- sculpting the body for perfection.

Slowing the aging process could be obtained partially through the use of the following vector:

- diet throw caloric restriction and nutrient density;

- exercise throw low-impact aerobic and anaerobic exercise;

- aggressive supplementation;

- mental exercises by focusing on reducing stress.

Achieving performance in specific workout programs by use of the following combination of body building characteristics:

- diet by using high-quality proteins and larger caloric intakes to build appropriate muscles \& replenish glycogen stores;

- exercise extensive practice of desired activities plus aerobic \& anaerobic crosstraining;

- performance-based supplementation;

- mental exercises by visualization.
Another important vector is that of building a good and healthy mental in harmony with the body parameters by use of:

- diet, using nutrient density and appropriate fatty acids like Omega3/Omega-6;

- primarily aerobic exercises;

- general supplementation, plus Omega-3 fatty acids and mental-performance supplements;

- mental exercises for achieving an important inside equilibrium.

Bodybuilders have another goal that of sculpting their body to boost their muscle system but not necessarily gaining strength through:

- diet having low caloric intake for weight loss or high-protein for muscle growth;

- primarily aerobic for weight loss or anaerobic for muscle growth;

- general supplementation like daily multivitamin;

- mental exercises by visual analysis of the body parts which must be workout regularly during exercises periods.

The idea of optimization is discussed in the context of trying to add more efficiency to our exercise programs. In order to determine if a workout was indeed optimized a tool for measuring is needed. So, for this reason different metrics could be built for determining the degree in which a workout was or not improved after applying optimization methods and techniques. A set of physiological metrics could be analyzed to determine if the working exercises were affecting in some way the body physiological parameters like weight, height, blood glucose level, resting heart rate, blood pressure and cholesterol.

The first step of the application is the Indexes Calculator, based on several inputs like weight $(\mathrm{Kg})$ and height $(\mathrm{cm})$ along with some fixed characteristics as age and sex provided when the user account is created. In Figure 5 is presented the interface which uses all the formulas mentioned above to provide the end results. The time interval must be smaller than 7 days, but the final length of the interval must be set it after a prior 
examination of the time needed for the body to adjust and change its characteristics after following the regime proposed by the application. Other validations are applied for the time interval and as well for the inputed data which must match a specific format.

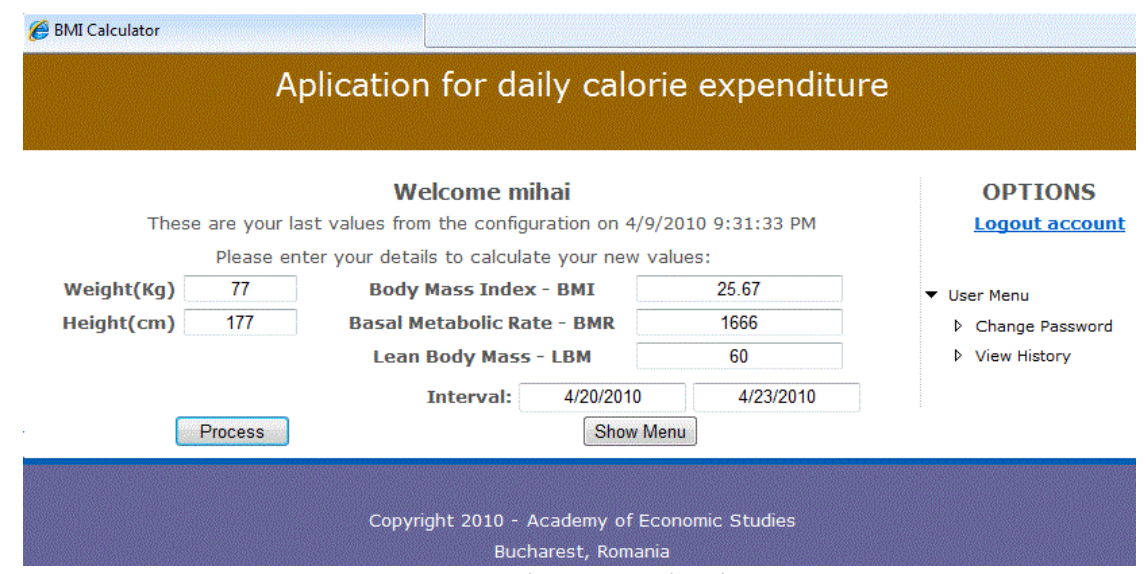

Fig. 2. Indexes Calculator

After the indexes were calculated the next step in application is to calculate the total daily need of calories based on the intensity effort defined for each day of the week as showed in Figure 6, representing the second set of input values which must be provided by the user, consisting in the allergies to which a user is sensitive, the effort intensity level for a particular day, the printing option of a specific menu calculated in the process.

\begin{tabular}{|c|c|c|c|c|c|c|}
\hline \multicolumn{7}{|c|}{$\begin{array}{c}\text { Menu Configuration } \\
\text { Choose your allergy: } \\
\square \text { Crustacee } \square \text { Alune } \square \text { Nuci } \square \text { Peste } \square \text { oua }\end{array}$} \\
\hline Days & Effort & & $\begin{array}{l}\text { Colories } \\
\text { Needed }\end{array}$ & Found Menu & Difference & $\begin{array}{c}\text { Printing } \\
\text { Option }\end{array}$ \\
\hline 6/9/2010 & Less Active & $\nabla$ & 2732.125 & $\underline{2735}$ & 2.875 & $\nabla$ \\
\hline $6 / 10 / 2010$ & Moderate & $\nabla$ & 3079.85 & 3084 & 4.15 & $\square$ \\
\hline $6 / 11 / 2010$ & Exortion & $\nabla$ & 3775.3 & $\underline{3767}$ & -8.3 & v \\
\hline
\end{tabular}

Fig. 3. Daily Calorie Calculator

In this point of application, presented in Figure 6, based on the five value intensity effort option, the daily calorie need is calculated along with the menus found for every day. More, the users can filter their menu choosing from a list of allergies which can cause them anaphylactic shocks, or they can print them in a Portable Document Format file, using the printing option. The SDACO application is providing users a reach set of ingredients and menus to help them understand the importance of a healthy diet which allows them to easily maintain their current level of weight or a preferred one prior defined in the application.

The algorithm used is based on the minimization of differences between the amount of calories needed for consumption reported to the intensity effort made and the total number of calories formed by summing each meal. The amount of calories needed for one day based on the type of effort made is calculated using the following formulas presented in Table 4: 
Table 4. Total daily energy expenditure - TDEE

\begin{tabular}{|l|c|c|}
\hline \multicolumn{1}{|c|}{ Category } & BMR coefficient & Description \\
\hline TDEE $_{\text {SEDENTARY }}$ & $1.2 \times \mathrm{BMR}$ & Sedentary activity - television or office work \\
\hline TDEE $_{\text {LESS ACTIVE }}$ & $1.375 \times \mathrm{BMR}$ & Light activity - exercise workout $1-3$ day per week \\
\hline TDEE $_{\text {ACTIVE }}$ & $1.55 \times \mathrm{BMR}$ & Moderate activity - exercise workout $3-5$ day per week \\
\hline TDEE $_{\text {VERY ACTIVE }}$ & $1.725 \times \mathrm{BMR}$ & High activity - exercise workout $6-7$ days per week \\
\hline TDEE $_{\text {EXCESSIVE }}$ & $1.9 \times \mathrm{BMR}$ & Extreme activity - exercise workout two times per day \\
\hline
\end{tabular}

Efficiency is given by the database usage which allows users to have lots of meals combinations covering almost all possibilities of effort intensity and BMR indexes.

This approach is useful for determining our body's needs for calories and gives precise directions in lowering, maintaining or growing our body fat mass implicit our weight.

The algorithm for generating the menus to meet the daily calorie level has the following steps:

A.calculating previous indicators to determine the input data for the algorithm, the daily calorie need, based on the effort intensity level for a determined period;

B. creating the vector off allergies to meet the individual requirements based on five major allergy categories: sea-shells, peanuts, tree nuts, fish and eggs, identified by [9];

C. choosing the menus from the database according with the allergy vector for each one of the menu types: Breakfast, Lunch First Meal, Lunch Second Meal, Lunch Dessert, Dinner Meal, Dinner Dessert by creating different arrays, $A_{k}, k=\overline{1,6}$ part of $X=A_{1} \times A_{2} \times A_{3} \times A_{4} \times A_{5} \times A_{6}$ the set of all solutions;

D. only the solutions that are allowable are chosen for each day of the interval; an allowable solution $x_{i j}$ is part of the set $\mathcal{A} \subseteq X \quad$ defined as $\mathcal{A}=\left\{x_{i j} \mid x_{i j} \in X,\left\|x_{i j}-T D I_{i}\right\|<\varepsilon\right\}, i=$ $\overline{1, n}, j=\overline{1, \operatorname{Card}(\mathcal{A})}$ and $\varepsilon=0.005 *$ $T D I_{i} ; \mathrm{n}$ - total number of days of the evaluation period; $T D I_{i}-$ total daily intake (kcal);

E. final menus are assembled and the results are presented assembled as a set of the tree major meals: breakfast, lunch with first, second meal and dessert and dinner with first meal and dessert as well having the option of printing in a Portable Document Format file.

For being more efficient and less time consuming due to the massive volume of menu combinations given by the Cartesian product off all menu sets, the distributed application can provide filtered sets of menus for the algorithm based on the allergy filters that a user can activate. As a solution is validated as allowable, the process is started again for the other remaining sets of values. Based on these three layers, the application is offering a diverse menu for each user based on their particularly needs and characteristics. For better results, an optimization can be made for the meal generating stage under which every meal will have an exact percentage of calories from the total amount. Studies had shown that our body needs calories distinctively by the day period as follows $30 \%$ of calories at breakfast, $50 \%$ of calories at lunch and $20 \%$ of calories at dinner. In this way equilibrium would be achieved and it will make us more efficient in our future research.

\section{Security Aspects of Informatics System}

An important security issues is deduced by monitoring the communications between the application's components. In the process of communication between different parts of the application, important and sometimes vulnerable information is vehiculated. The process of communication must be, in this sense, well managed, taking care that there's no possibility to gain control over the resources using sensitive data, skipped to end-users in the communication process [2]. Some of the ways of accessing data from the communication process between application 
components is by checking the following objects for any sensitive material:

- URL's - the internet addresses used to navigate through the application; sensitive information can be revealed in this region as part of the web submission process of a form through the GET method;

- Cookies - temporally client-side files used for storing different setting data for the web based distributed application.

In the process of transferring information about the daily menus for showing menu suggestions, the following syntax, $S 1$, for the URL is used by the application:

Sl=http://www.webserver/pathASPXfile?par am $1=$ value $1 \&$ param $2=$ value $2 \& . . \&$ param 7 =value 7 , where:

- webserver - icnc.ase.ro;

- pathASPXfile - application file path of the requested resource;

- $\operatorname{param}_{i}, i=\overline{1,7}$ - the parameters' names for sending menu ID's for the next resource;

- value $_{i}, i=\overline{1,7}$ - the parameters' values consisting in menu ID's and day ID.

Having these types of information at its disposal, a user can actually see throughout the whole sets of menus, just by modifying the parameters values and submitting again a valid request to the web server. In this sense, an optimization in terms of minimizing the value of the indicator Degree of Sensitive Data, DSD is required:

where:

$$
D S D=1-\frac{T S D P(K b)}{T S D(K b)}
$$

TSDP - amount of sensitive data which is protected by user's access;

TSD - amount of total sensitive data vehiculated by the application.
The DSD indicator takes values between $[0 ; 1)$ in the following scenarios:

- $D S D=0$, when all sensitive information vehiculated in the application is protected;

- $\lim _{T S D P \rightarrow 0} D S D=1 \quad$ because $\lim _{T S D P \rightarrow 0} \frac{T S D P}{T S D}=0$ and $D S D=1-0 \Rightarrow$ $D S D=1$.

An implementation of this optimization process was conducted in the application by encrypting the URL syntax presented above with an open source encryption algorithm found to be most efficient in [10]:

The security optimization process takes place under the following step procedure:

A. identifying the parameters' values and creating the $S 1$ URL syntax;

B. encrypting $S 1$ into $S 2$ by means of the encryption function $O T P(S 1)=S 2$;

C. creating the new URL, $S 3$ from $S 2$, based on the URL Base64 Encoding representation for being able to be sent over the internet;

D. the host page gets the URL S3 syntax from the request object of the page and decodes it from the Base64 representation, transforming it into S2 encrypted state;

E. from the encrypted S2 state, the mirror encryption operation takes place, as the OTP are symmetric class algorithms, and the final S1 syntax is decoded;

F. the S1 syntax will serve to successfully retrieve all the menu ID's and day ID for showing the final results as a complete menu suggestion.

The final URL syntax which travels the network and is transparent to the user is like S3=http://www.icnc.ase.ro/User/MenuDetail. aspx? pass $=$ ARaQQtorYdYiL7wHrQusDs4Do $8 W r t Q 2$. Table 5 shows an improvement of the $D S D$ indicator due to growth of the TSDP value.

Table 5. DSD Optimization Chart

\begin{tabular}{|c|c|c|}
\hline Without Security & Relation & With Security \\
\hline $\operatorname{TSDP}_{0}(\mathrm{~Kb})$ & $<$ & $\operatorname{TSDP}_{1}(\mathrm{~Kb})$ \\
\hline$\frac{T S D P_{0}(K b)}{T S D(K b)}$ & $<$ & $\frac{T S D P_{1}(K b)}{T S D(K b)}$ \\
\hline $1-\frac{T S D P_{0}(K b)}{T S D(K b)}$ & $>$ & $1-\frac{T S D P_{1}(K b)}{T S D(K b)}$ \\
\hline
\end{tabular}


Table 5 shows that $D S D_{1}<D S D_{0}$, meaning an optimization of the DSD as it was defined.

\section{Conclusions}

The paper mixes a practical approach based on an informatics support in order to identify new ways of adding efficiency to body modeling activities. After a detailed presentation of how biological mechanisms influence the chemical processes in the human body an automatic system is presented in order to help bodybuilders to keep track of their calorie consumption in relation to the level of physical effort. Security issues of this system are exposed because sensitive information is vehiculated between the modules of such application.

\section{References}

[1] C. O. Mănescu, „Suplimente nutriţionale și doping în sport", Ed. ASE, București, 2010, pp. 36-38.

[2] C. Boja, M. Doinea, "Security assessment of a web distributed application", Informatica Economica Journal, Vol. 14, No. 1, 2010, pp. 152 - 162, ISSN 1453-1305

[3] T. C. Netzer, "The complete Book of Food Counts 8th Edition", Dell Book Press, 2008, 944 pg., ISBN 9780440243205

[4] Food calorie list, 2009, [Online] http://www.weightlossforall.com/foodcalorieslist.htm

[5] (2009, Aug.) America's Authority of Fitness.

[Online]: http://www.acefitness.org/FITFACTS/fit facts_display.aspx?itemid $=322$

[6] M. Doinea, "Distributed application for calories optimization", Body Building Science Journal, Vol. 1, No. 1, 2009, pg. 72 - 83, ISSN 2066-8007

[7] M. Doinea, "Analysis upon the influences of calories on the human body", Body Building Science Journal, Vol. 1, No. 2, 2009, pp. 76 - 83, ISSN 2066-8007

[8] WHO expert consultation, "Appropriate body-mass index for Asian populations and its implications for policy and intervention strategies", The Lancet Journal, Vol. 363, No. 9403, 2004, 157$163 \mathrm{pp}$.

[9] National Institute of Allergies and Infectious Diseases, Online Resource http://www.niaid.nih.gov/topics/foodAll ergy/Documents/foodallergy.pdf, 2007

[10] M. Doinea, "Comparative Analysis of Performance Encryption and Decryption Open Source Procedures using OTP cryptographic Class Algorithms", Open Source Science Journal, Vol. 1, No. 2, 2009, pp. 31-46, ISSN 2066 - 740X

[11] P.O. Astrand, "Endurance in sport", The enciclopedy of sports medicine, 1992.

[12] L. Bonci, "Sports nutrition for coaches", Human Kinetics, 2009.

[13] L. Burke, "Practical sports nutrition", Human Kinetics, 2007.

[14] Clark, N., "Sports nutrition guidebook", 2008

[15] P.J. D'Amato, "Eating right for your type", Ed. G.P. Putnam's Sons, 1996

[16] A. De Lorenzo, "Effect of acute and chronic branched-chain amino acids on energy metabolism and muscle performance.", Diabetes Nutr Metab., 2003 Oct-Dec;16(5-6):291-7.

[17] I. Drăgan, "Medicina sportivă aplicată", Ed. Editis, 1994

[18] I. Drăgan et al, "Researches concerning the antioxidant effects of a new compound in top athletes.", The Second World IOC Congress on Sport Medicine, Barcelona, 1991.

[19] I. Drăgan, "Medicină sportivă.", Ed. Medicală, București, 2002.

[20] I. Drăgan, V. Stroescu, "Medicaţia în efortul fizic", Ed. Editis, București, 1993.

[21] M. Dunford, "Fundamentals in exercise and sports nutrition", H. Kinetics, 2010.

[22] R. Dumitrescu, "Culturism-fitness, fundamente teoretice și practicometodice.", Ed. Universității, 2008.

[23] S.E. Girard, "Endurance sport nutrition", 2009.

[24] R. Flandrois, "Medicine du sport.", Ed. Vigot, Paris, 1986. 
[25] B. Foran, "High performance in sports conditioning.", Human Kinetics, 2001.

[26] D.K. Layman, "Egg Protein as a Source of Power, Strength, and Energy.", Nutrition Today, 44(1) 2009, pp. 43-48.

[27] C.O. Mănescu, "Suplimente nutriționale şi doping în sport.", Editura ASE, 2010.

[28] S. E. Riechman, "Dietary Cholesterol and Skeletal Muscle Hypertrophy with Resistance Training: A Randomized Placebo-Controlled Trial", FASEB, 2008.

[29] D. Sandler, "Sports power.", Human kinetics, 2005.

[30] W. Schanzer, "Doping nuovi sviluppi e problematiche", Scuola di sports, 1998.

[31] D. Șerban, "Superfit. Esențialul în fitness și culturism”, Ed. Corint, 2006.

[32] R.H. Strauss, "Medicaments et performances sportives", Ed. Masson, 1990.

[33] V. Stroescu, "Bazele farmacologice ale practicii medicale", Ed. Medicală, 1998.

[34] T. Todd, "Anabolic Steroids", Journal of sport history, 14, 1987.

[35] A. Tremblay, "Impact of exercise intensity on body fatness and skeletal muscle metabolism.", Metabolism, 1994 Jul;43(7):814-8.
[36] P. Tschiene, "Transformarea efectelor antrenamentului sau adaptarea pe termen lung prin effort", Leistungssport, nr.6, 1993.

[37] V. Tudor, "Capacităţi condiţionale, coordinative şi intermediare", Editura Coresi, București, 1998.

[38] V. Tudor, D.I. Crișan, "Forţa, aptitudine motrică", Ed. Bren, București, 2007.

[39] F. Uceanu, "Culturism de performanță", Ed. Redis Club, 2001

[40] A.J. Van Vught, "Effects of Oral Ingestion of Amino Acids and Proteins on the Somatotropic Axis.", J Clin Endocrinol Metab, February 2008, 93(2):584-590.

[41] G.E. Vâjială, M. Lamor, "Doping antidoping”, Ed. FEST, București, 2002.

[42] J.S. Volek, "Body composition and hormonal responses to a carbohydraterestricted diet.", Metabolism, 2002 Jul;51(7):864-70.

[43] J. S. Volek and S. E. Forsythe, "The case for not restricting saturated fat on a low carbohydrate diet", Nutrition \& Metabolism, Vol. 2, No. 21, 2005.

[44] J. Weineck, "Biologie du sport", Ed. Vigot, Paris, 1992.

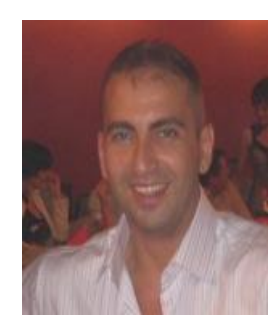

Dan Cristian MĂNESCU is a PhD Lecturer to Academy of Economic Studies. His $\mathrm{PhD}$ thesis approaches the field of bodybuilding and physical development, with clear objectives in optimisation of practice. His research is also backed up by a master diploma in Performance Training. He is a lecturer assistant, training fitness and bodybuilding at the Academy of Economic Studies. He published 4 books and 30 articles as single author and his research interests are directed to area of fitness and bodybuilding, nutrition and supllementation.

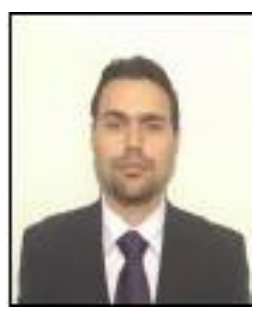

Mihai DOINEA is a PhD Assistant Lecturer within Bucharest University of Economic Studies. His $\mathrm{PhD}$ thesis approaches the field of Informatics Security with clear objectives in finding security optimization methods for distributed applications. His research is also backed up by a master diploma in Informatics Security (2006). He is a lecturer assistant, teaching Data Structures, Advanced Programming Languages, Mobile Application Programming. He published more than 30 articles in collaboration or as single author and his research interests are directed to areas such as security, distributed applications, artificial intelligence and optimization algorithms. 